\title{
Ductile-brittle transition behaviour of PLA/o-MMT films during the physical aging process
}

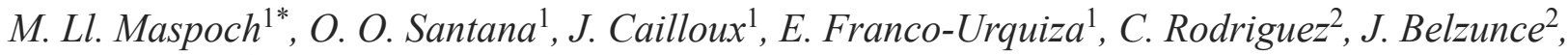 \\ A. B. Martínez ${ }^{1}$ \\ ${ }^{1}$ Centre Català del Plàstic (CCP), Universitat Politècnica de Catalunya (ETSEIB-UPC), C/Colom 114, 08222 Terrassa, \\ Spain \\ ${ }^{2}$ SIMUMECAMAT, Universidad de Oviedo, Edificio Departamental Oeste, n 7, 33203 Gijón, Spain
}

Received 15 September 2014; accepted in revised form 20 November 2014

\begin{abstract}
The ductile-brittle transition behaviour of organo modified montmorillonite-based Poly(lactic acid) films (PLA/o-MMT) was analysed using the Essential Work of Fracture (EWF) methodology, Small Punch Tests (SPT) and Enthalpy relaxation analysis. While the EWF methodology could only be applied successfully to de-aged samples, small punch test (SPT) was revealed as more effective for a mechanical characterization during the transient behaviour from ductile to brittle. According to differential scanning calorimetry (DSC) results, physical aging at $30^{\circ} \mathrm{C}$ of PLA/o-MMT samples exhibited slower enthalpy relaxation kinetics as compared to the pristine polymer. Although all samples exhibited an equivalent thermodynamic state after being stored one week at $30^{\circ} \mathrm{C}$, significant differences were observed in the mechanical performances. These changes could be attributed to the toughening mechanisms promoted by o-MMT.
\end{abstract}

Keywords: nanocomposites, PLA, physical aging, fracture and fatigue

\section{Introduction}

Over the past ten years, Poly(lactic acid) (PLA) has gained much interest in commercial applications. The ring-opening polymerization of lactic acid is the current method to obtain PLA of high molecular weight [1]. It is a high strength and high modulus aliphatic thermoplastic biopolymer with mechanical properties ranging between those of Polystyrene (PS) and Poly(ethylene terephthalate) (PET) [2, 3]. However, some other properties such as its low melt stability throughout processing due to hydrolytic degradation reactions, low melt strength, low heat distortion temperature (HDT) and its high brittleness reduce its use to very limited applications [4]. As already established by numerous research groups, different strategies may be used to mitigate these drawbacks. In this way, the addition of plasticizers, copolymerization, melt blending with other thermoplastics, reactive extrusion combined with multifunctional reactive agents and (nano)composites have demonstrated encouraging results [5-8].

PLA parts are usually found in their amorphous state due to the relatively fast cooling rates of industrial processes as compared to the crystallization rates of current commercial PLA grades [9]. As PLA parts are employed at temperatures below but close to $T_{\mathrm{g}}$, these thermodynamically unstable glasses rapidly tend toward an equilibrium state through slow segmental rearrangements over time. This phenomenon is commonly referred to as 'physical aging', which promotes a ductile to brittle transition in mechanical and fracture behaviour. The resulting brittleness

\footnotetext{
${ }^{*}$ Corresponding author, e-mail: maria.1luisa.maspoch@upc.edu (C) BME-PT
} 
does not only affect the end use behaviour but also the handling and processing, leading to important limitations in large-scale production [10,11].

Over the last years, numerous studies have reported the effect of the physical aging on the PLA properties. $[12,13]$. Nevertheless, there are few works describing the effect of physical aging on the fracture behaviour of PLA using Fracture Mechanics approaches. It has been shown that the EWF methodology is a useful tool to investigate the effect of physical aging on PET and Glycol-modified Poly (ethylene terephthalate) (PETG) films [14-16]. In the case of PLA, which has faster physical aging than PET and PETG, the EWF analysis can only be successfully applied in the non-aged material. After 1 hour of de-aging treatment, a transient ductile-brittle situation is observed, and each tested sample shows a different behaviour $[17,18]$.

The EWF methodology is frequently placed at the forefront of the post-yielding fracture characterization. However, this technique is laborious and time consuming. The main difficulties arise from the preparation and the evaluation of a large number of notched specimens. Since PLA exhibits a fast physical aging, sample conditioning and experimentation should be performed quickly.

Recently, the small punch test (SPT) has seen significant developments as an alternative to conventional mechanical testing procedures. SPT method provides specific advantages as compared to the EWF procedure. For instance, both specimen sizes and test times are lower in SPT than in EWF methodology. Although this method has been largely used in the field of steels and some metallic alloys, only few works report the investigation of polymeric materials [19, 20]. Rodriguez et al. [21] reported a correlation between the mechanical (Elastic modulus, Yield stress) and SPT parameters normalized by sample thickness $(t)$ for PLA films. Moreover, the authors intended to correlate the specific essential work of fracture $\left(w_{\mathrm{e}}\right)$ with the normalized mechanical work at break using SPT.

This work aims to evaluate the applicability of the SPT to study the ductile-brittle transition of PLA films with two different contents of organically modified montmorillonite (o-MMT) during the physical aging process. In addition, the effect of the o-MMT on the PLA physical aging kinetics was investigated.

\section{Experimental}

\subsection{Materials and processing}

A commercial PLA extrusion grade (Ingeo 2002D ${ }^{\circledR}$, NatureWorks, Arendonk, Belgium) characterized by a MFI $\left(210^{\circ} \mathrm{C} / 2.16 \mathrm{~kg}\right)$ of $5.8 \pm 0.2 \mathrm{dg} / \mathrm{min}$ and a nominal D-enantiomer lactide content of $4.25 \% \mathrm{~mol}$. was used in this study. An organically modified montmorillonite (o-MMT) clay (Cloisite ${ }^{\circledR}$ 30B) purchased from Southern Clay Products (USA) in powder form was used as a filler. The clay was modified with a Methyl-tallow-bis-2-hydroxyethyl ammonium salt (MT2EtOH) and was characterized by a density of $1.98 \mathrm{~g} \cdot \mathrm{cm}^{-3}$, loss on ignition of about $30 \mathrm{wt} \%$ and an interlaminar distance $d_{001}$ of $1.85 \mathrm{~nm}$. Melt compounding of the o-MMT and PLA was performed in a twin-screw extruder $25 \mathrm{~mm} L / D=36$ (KNETER 25X24D, COLLIN, Ebersberg, Germany). The screw speed was set to $85 \mathrm{rpm}$ and the temperature profile was established from $145^{\circ} \mathrm{C}$ in the feed section to $200^{\circ} \mathrm{C}$ in the die. Films with a nominal thickness $(t)$ of $400 \mu \mathrm{m}$ and $100 \mathrm{~mm}$ nominal width were calendered (Techline CR72T, COLLIN, Ebersberg, Germany).

Prior to processing, PLA was dried for $3 \mathrm{~h}$ at $80^{\circ} \mathrm{C}$ in a hopper-dryer (DSN 506HE, Piovan, Venice, Italy) with a dew point of $-40^{\circ} \mathrm{C}$ and kept under the same conditions during the whole process. o-MMT was dried at $130^{\circ} \mathrm{C}$ for 22 hours using a convection oven (J. P. Selecta, S. A., Barcelona, Spain).

Using the above described processing parameters, two PLA/o-MMT films were obtained with a mean o-MMT concentration of $0.5 \pm 0.1 \mathrm{wt} \%$ (PLA-C 0.5 ) and $2.5 \pm 0.1 \mathrm{wt} \%$ (PLA-C2.5). Using similar extrusion conditions, neat PLA (PLA) films were prepared. More details on films manufacturing can be found in [22].

Previous studies showed that under the used processing conditions, all films were amorphous, according to the differential scanning calorimetry (DSC) results obtained from the first heating cycle (30$200^{\circ} \mathrm{C}$ ) at $10^{\circ} \mathrm{C} \cdot \mathrm{min}^{-1}$. On the other hand, Transmission Electronic Microscopy (TEM) analysis exhibited a homogeneous distribution of o-MMT particles, irrespective of its contents (Figure 1a), with some intercalation and exfoliation (Figure 1b) which was verified by WAXS tests [22].

A 'De-aging' thermal treatment was applied to the films in order to release internal stresses and to avoid excessive defects during sample cutting due 


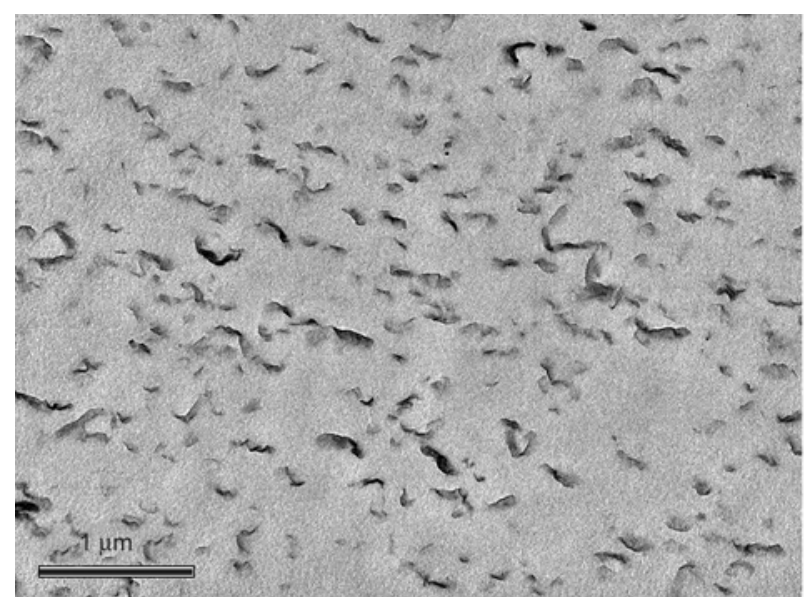

a)

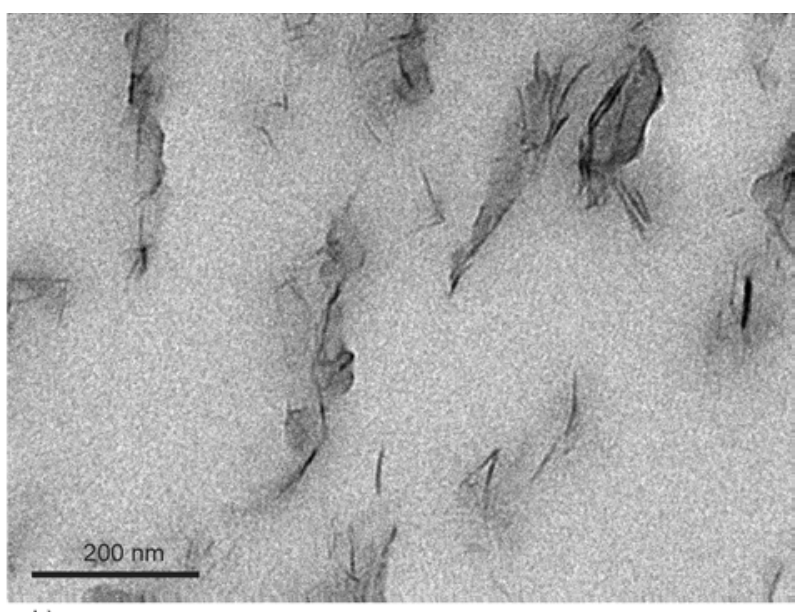

b)

Figure 1. TEM micrograph of PLA films with $2.5 \mathrm{wt} \%$ of o-MMT (PLA-C2.5). a) general view $(\times 17$ 000) and b) higher magnification view $(\times 90000)$.

to their pronounced brittleness. Films were heated to $60 \pm 1{ }^{\circ} \mathrm{C}$ for $20 \mathrm{~min}$ in a convection oven (J. P. Selecta, S. A., Barcelona, Spain) and subsequently quenched in an ice water bath $\left(2 \pm 2^{\circ} \mathrm{C}\right)$ for $5 \mathrm{~min}$. After drying, specimens for the mechanical and fracture tests were immediately extracted from the centre of the films. Prior to testing, several sample sets were stored at room conditions $\left(23 \pm 2^{\circ} \mathrm{C}, 50 \% \mathrm{RH}\right)$ for different aging times $\left(t_{\mathrm{a}}\right)$ ranging from $10^{4}$ to $2.6 \cdot 10^{5} \mathrm{~min}$.

Mechanical and fracture tests were carried out on samples aged for different $t_{\mathrm{a}}$. 'De-aged' samples (referred to as Da) were tested immediately after the end of the thermal treatment $\left(t_{\mathrm{a}}=0 \mathrm{~min}\right)$. A period of 6 months $\left(t_{\mathrm{a}}=2.6 \cdot 10^{5} \mathrm{~min}\right)$ was verified as sufficiently long to reach a mechanically stable aged state (i.e. regardless of $t_{\mathrm{a}}$, all tested samples exhibited similar deformation behaviours and consistent mechanical parameters). This group of samples was referred to as 'equilibrated aged' samples.

\subsection{Essential work of fracture (EWF) tests}

The fracture characterisation was based on the PostYielding Fracture Mechanics through the Essential Work of Fracture (EWF) methodology. The theoretical basis, experimental procedure and data reduction have been extensively described in the previous works of Martinez et al. [23], Bárány et al. [24] and the ESIS-TC4 test protocol [25]. The fracture parameters are obtained from linear fitting of the specific work of fracture $\left(w_{\mathrm{f}}\right)$ vs. ligament length $(l)$. From the linear regression, the specific essential work of fracture $\left(w_{\mathrm{e}}\right)$ and the non-essential or 'plastic' term $\left(\beta w_{\mathrm{p}}\right)$ are obtained using Equation (1): $w_{\mathrm{f}}=w_{\mathrm{e}}+\beta w_{\mathrm{p}} l$

Three main preconditions have to be fulfilled in order to properly analyse the EWF results: (1) $(l)$ of the specimens should be in a range that guarantees a full ligament yielding prior to the crack propagation onset; (2) a self-similarity of the load-displacement curves between each ligament length should be observed to ensure a similar fracture process between all samples; and (3) the process should take place in a pure plane-stress state condition for the whole range of $l$ considered [23-25].

In this work, EWF analysis was performed using deeply double-edge notched tension (DDENT) specimens. Samples were extracted from the centre of the film, parallel to the MD direction and using the following dimensions: Length $L=100 \mathrm{~mm}$, width $W=50 \mathrm{~mm}$. The considered nominal ligament length $\left(l_{\mathrm{n}}\right)$ was in the range of 4 and $26 \mathrm{~mm}$. Prior to testing, initial cracks were sharpened using a fresh razor blade.

Fracture tests were carried out on a universal testing machine (SUN 2500, GALDABINI, Cardano al Campo, Italy) equipped with a $5 \mathrm{kN}$ load cell at a constant crosshead speed of $1 \mathrm{~mm} / \mathrm{min}$ and at $23 \pm 2^{\circ} \mathrm{C}$ and $50 \% \mathrm{RH}$. The displacement was measured using a video extensometer (OS-65D CCD, Minstron, Taipei, Taiwan) coupled to a Windows-based software (Messphysik, Material Testing, Fürstenfeld, Austria), according to the procedure described in a previous work [26].

After testing, a binocular microscope (Carton, Pathumthani, Thailand) was used to determine the 
accurate ligament lengths $(l)$ and to observe the whole deformation and fracture process zone.

In order to make the self-similarity verification and selection of valid load $(P)$-displacement $(d)$ traces from fracture tests, curves of nominal engineering stress $\left(\sigma_{\mathrm{N}}\right)$ (Equation (2)) against normalized displacement $\left(d_{\mathrm{N}}\right)$ (Equation (3)) for each group of samples were constructed. Those curves that did not overlap until the crack onset propagation region within a $5 \%$ confidence band or showed some unexpected cross in the propagation (tear) region were discarded.

$$
\sigma_{\mathrm{N}}=\frac{P}{l \cdot t_{\mathrm{r}}}
$$

$d_{\mathrm{N}}=\frac{d}{l}$

Fracture surfaces of selected DDENT specimens were inspected using scanning electronic microscopy (SEM) JEOL JSM 5610 (Jeol, Tokyo, Japan) with an acceleration voltage of $10 \mathrm{kV}$. The fracture surfaces were sputter coated with a thin $\mathrm{Au} / \mathrm{Pd}$ layer using a Bal-Tec SCD005 Sputter Coater (Bal-Tec, Liechtenstein).

\subsection{Small punch tests}

In Figure 2 is sketched the experimental SPT mechanism with the sample geometry and dimensions. The punch was connected to an universal testing machine (MTS Sinergy, Roissy-en-Brie, France) equipped with a $5 \mathrm{kN}$ load cell. Samples are placed on the lower matrix, which has a $4 \mathrm{~mm}$ diameter hole with a $0.2 \mathrm{~mm}$ fillet radius. The specimen is firmly clamped by means of a threaded fixer and the load is applied by a $2.5 \mathrm{~mm}$ hemispherical diameter

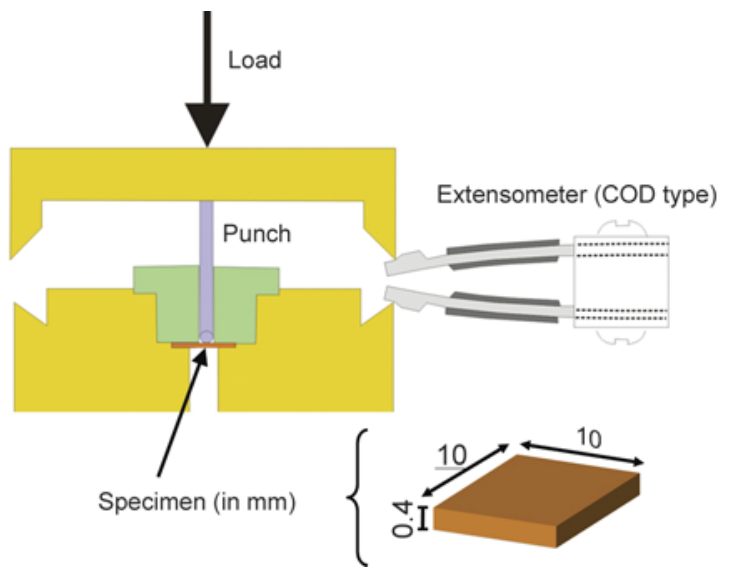

Figure 2. Sketch of the SPT device used and specimen dimensions punch. A COD type extensometer is used to measure the punch displacement $(d)[27,28]$.

Tests were carried out at room conditions $\left(23 \pm 2{ }^{\circ} \mathrm{C}\right.$ and $50 \% \mathrm{RH}$ ) and at constant crosshead speed of $0.2 \mathrm{~mm} \cdot \mathrm{min}^{-1}$. The specimens were tested at different physical aging times $\left(t_{\mathrm{a}}\right)$ as described in section 2.1. A minimum of ten samples were used to characterise each material at each $t_{\mathrm{a}}$. The mechanical work at break $\left(W_{\mathrm{b}}\right)$ was calculated as the area up to the rupture point of the load-punch displacement curves. $W_{\mathrm{b}}$ was normalized by the squared of the specimen thickness $(t), W_{\mathrm{b}} / t^{2}$.

\subsection{Thermal characterization}

The effect of o-MMT on the rate of physical aging at $30^{\circ} \mathrm{C}$ was investigated using a differential scanning calorimeter (DSC) (Pyris 1 coupled to a $2 \mathrm{P}$ intracooler, Perkin Elmer, Waltham, MA, USA) under a dry nitrogen atmosphere. Temperatures as well as heat of transition were calibrated with lead and indium at $10^{\circ} \mathrm{C} / \mathrm{min}$.

About 5-6 mgs of each material were encapsulated in aluminium pans. A total of 8 thermal cycles as shown in Figure 3 was performed with the following ta: $0,10,30,70,100,300,700$ and $1000 \mathrm{~min}$. The last heating scan (ramp c) was programmed to record the DSC trace of the aged sample. For an aging time of $10^{4} \mathrm{~min}$ (7 days) the thermal treatment was performed using an encapsulated sample and stored in a controlled convection oven.

In order to improve accuracy and to minimize the errors brought by baseline fluctuations and calibrations, this procedure were repeated three times using fresh samples taken from different zones of the film.

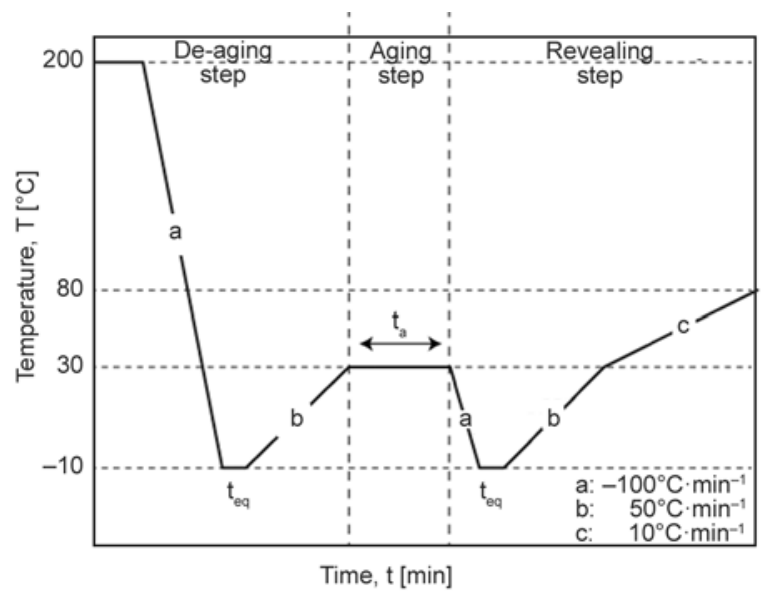

Figure 3. DSC thermal protocol used to investigate the rate of enthalpy relaxation at $30^{\circ} \mathrm{C}$ 
The thermal fatigue degradation of samples was verified after completing the thermal protocol. Such verification was performed according to the procedure described in a previous work [17].

From the heating scan of ramp c, the enthalpy relaxation (or enthalpy recovery) $\left(\delta_{\mathrm{H}}\right)$ for each aging time $\left(t_{\mathrm{a}}\right)$ was calculated as the difference in area between the heating scan of isothermally aged samples and the heating scan of the quenched reference sample. The overall enthalpy relaxation rate $\left(\beta_{\mathrm{H}}\right)$ of a bulk sample, which is a reasonable indicator of the aging kinetics, may be estimated from the slope of $\delta_{\mathrm{H}}$ as a function of the $\log t_{\mathrm{a}}$ according to Equation (4) [13, 29]:

$\beta_{\mathrm{H}}=\frac{\mathrm{d} \delta_{\mathrm{H}}}{\mathrm{d}\left(\log t_{\mathrm{a}}\right)}$

As a result of the current aging temperature $\left(30^{\circ} \mathrm{C}\right)$, a significant annealing time was required to reach a complete material structural equilibrium. Therefore, freshly de-aged samples were aged for 6 months at room temperature $\left(23 \pm 2^{\circ} \mathrm{C}, 50 \% \mathrm{RH}\right)$ and thereafter heated from 30 to $80^{\circ} \mathrm{C}$ at $10^{\circ} \mathrm{C} \cdot \mathrm{min}^{-1}$ in order to reveal their aged state.

\section{Results and discussion}

Figure 4 shows typical engineering stress $\left(\sigma_{\mathrm{N}}\right)$ vs. normalized displacement $\left(d_{\mathrm{N}}\right)$ curves obtained from the EWF tests of de-aged $\left(t_{\mathrm{a}}=0 \mathrm{~min}\right)$ and 'equilibrated aged' ( $t_{\mathrm{a}}=6$ month) samples.

Using a Digital Image Correlation (DIC) analysis $[17,18]$, it was observed that for both groups of sample, the yielding process was initiated well before the maximum load was reached and from both sharpened cracks. As an example, the crack propagation onset was observed at the point indicated by the arrows as shown in Figure 4. Although 'de-aged' samples (Figure 4a) showed full ligament yielding before crack propagation, 'equilibrated aged' samples (Figure 4b) exhibited the crack propagation onset prior to the complete plastic collapse of the ligament.

According to Bárány et al. [24], 'the best EWF model material' would show a curve similar to the one observed in Figure 4a. This is usually obtained from amorphous polymers which are prone to fail by shear yielding in the used test conditions. The last observation could invalidate the applicability of the EWF concept for the 'equilibrated aged' samples (Figure 4b).
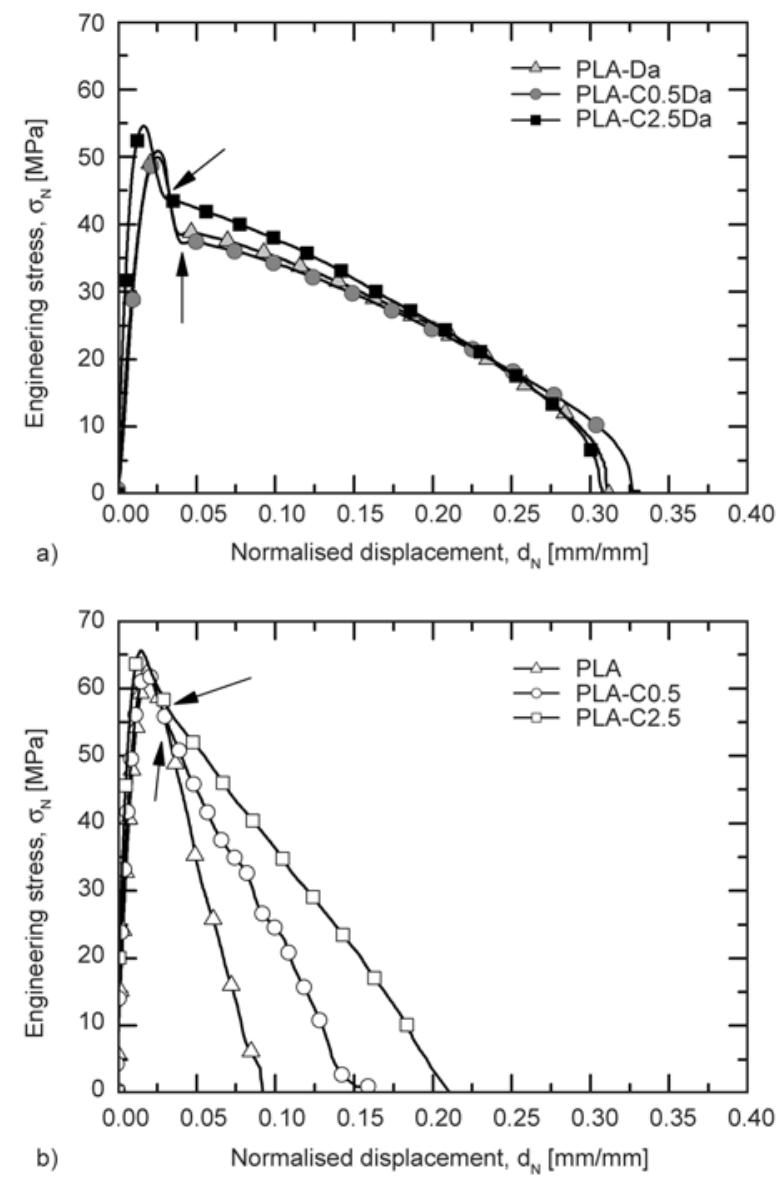

Figure 4. Typical engineering stress $\left(\sigma_{\mathrm{N}}\right)$ vs. normalized displacement curves $\left(d_{\mathrm{N}}\right)$ for (a) De-aged $\left(t_{\mathrm{a}}=\right.$ $0 \mathrm{~min})(\mathrm{Da})$ and (b) 'equilibrated aged' $\left(t_{\mathrm{a}}=\right.$ 6 months) DDENT samples. $l_{\mathrm{n}}=15 \mathrm{~mm}$. Arrows indicate the onset of crack propagation.

Qualitatively, it can be seen that the largest differences are observed for 'equilibrated aged' samples, especially in the tearing stage (crack propagation). As shown in Figure 4b, PLA-C2.5 seems to show a greater tear resistance as compared to PLA and PLAC0.5. For de-aged samples, these differences seem to be minimized due to the large similarity between all measurements. However, it is obvious that the stress level required to initiate the crack propagation was superior for PLA-C2.5Da samples.

Although 'equilibrated aged' samples did not fulfil all EWF analysis requirements, a comparative quantitative study of the performance of the composite films under these two thermodynamic conditions was performed using the EWF methodology.

As shown in Figure 5, both groups of samples showed a linear relationship between $w_{\mathrm{f}}$ and $l$, which allows the calculation of the parameters we and $\beta w_{\mathrm{p}}$ (c.f. Equation (1)). Results are compiled in Table 1. 


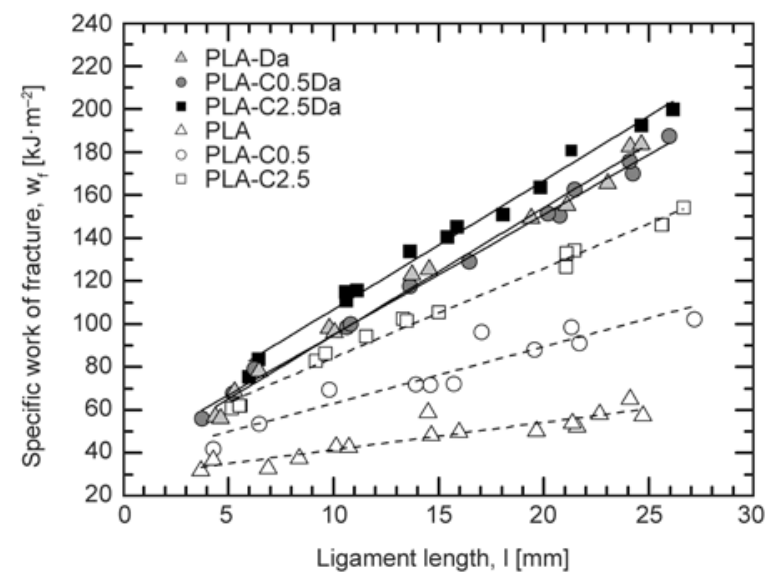

Figure 5. Specific work of fracture $\left(w_{\mathrm{f}}\right)$ vs. ligament length $(l)$ for all investigated samples

Table 1. Fracture parameters obtained from the specific work of fracture analysis

\begin{tabular}{|c|c|c|c|}
\hline Material & $\begin{array}{c}w_{\mathrm{e}} \\
{\left[\mathrm{kJ} \cdot \mathrm{m}^{-2}\right]}\end{array}$ & $\begin{array}{c}\boldsymbol{\beta} \boldsymbol{w}_{\mathrm{p}} \\
{\left[\mathbf{M J} \cdot \mathbf{m}^{-3}\right]}\end{array}$ & $R^{2}$ \\
\hline \multicolumn{4}{|c|}{ 'De-aged' $\left(t_{\mathrm{a}}: 0\right.$ min $)$} \\
\hline PLA-Da & $36 \pm 3$ & $5.9 \pm 0.2$ & 0.990 \\
\hline PLA-C0.5Da & $39 \pm 2$ & $5.6 \pm 0.1$ & 0.995 \\
\hline PLA-C2.5Da & $47 \pm 2$ & $6.0 \pm 0.2$ & 0.989 \\
\hline \multicolumn{4}{|c|}{ 'Equilibrated aged' ( $t_{\mathrm{a}}: 6$ months) } \\
\hline PLA & $29 \pm 3$ & $1.3 \pm 0.2$ & 0.820 \\
\hline PLA-C0.5 & $37 \pm 5$ & $2.6 \pm 0.3$ & 0.885 \\
\hline PLA-C 2.5 & $43 \pm 3$ & $4.2 \pm 0.1$ & 0.990 \\
\hline
\end{tabular}

According to the correlation coefficient $\left(R^{2}\right)$ values, de-aged samples exhibited the best linear fitting.

The obtained results confirm the previous observations made from the preliminary analysis of $\sigma_{\mathrm{N}} \mathrm{vs}$. $d_{\mathrm{N}}$ curves:

- Although slight differences were observed between all fracture parameters for 'de-aged' samples, PLA-C2.5Da exhibited the highest we value.

- A greater influence of the o-MMT particles on the fracture parameters was observed for 'equilibrated aged' samples. With increasing the o-MMT amount, the fracture parameters increased, which is apparently observed for the non-essential term $\left(\beta w_{\mathrm{p}}\right)$, commonly associated to the crack propagation resistance.

Regarding 'equilibrated aged' samples, a physical meaning can be correlated to the observed trend if the deformation process is considered. According to Karger-Kocsis and Czigány [30], shear banding via network stretching appeared to be the dominant deformation mechanism in the whole fracture and deformation process zone of amorphous thermoplastic polyesters. After being placed PLA and PLA-Da tested samples above $T_{\mathrm{g}}\left(60^{\circ} \mathrm{C}\right)$ for $10 \mathrm{~min}$, this net- work stretching mechanism was confirmed for both groups due to the complete recovery of the stretched region. However, when similar experiments were applied to the PLA-oMMT samples, partial recovery was observed which indicates that some true plastic or irreversible deformation micro-mechanism was operating.

Figure 6 depicts optical micrographs of the fracture process zone of all 'equilibrated aged' samples. While PLA samples exhibited several long crazes surrounding the plane of crack propagation, this scenario substantially changed when o-MMT was added. By increasing the o-MMT content, the size of the whitening zone was enlarged. A larger proportion of shorter crazes was observed, which became thinner and better defined as the clay content increased (c.f. Figures $6 \mathrm{~b}$ and $6 \mathrm{c}$ ). This behaviour is frequently associated to an increasing content of irreversible deformation micro-mechanisms in the Outer 'Plastic' Deformation Zone (OPDZ).

The fractured surfaces of all 'equilibrated aged' samples were observed using SEM as shown in Figure 7. Ahead of the crack tip, PLA samples (Figure 7a) showed a typical brittle topography with a smooth surface. This aspect was due to the formation of long crazes as deformation micro-mechanism. Nevertheless, an increasing content of voiding and plastic deformation was observed with increasing o-MMT amount for PLA/o-MMT films. These observations suggest that the deformation process in the composite films results from a combination of matrix crazing and o-MMT/matrix debonding in form of voiding (cavitation) which releases the local triaxiality. For further loading, these voids and crazes grew with extensive fibrillation (shear yielding), which gives rise to the distortion and coalescence of the holes (c.f. Figure $7 \mathrm{~b}$ and $7 c)$ with ridge formation. Similar observations have been reported in Poly(propylene-block-ethylene) (EPBC) and PETG modified with several types of nanofillers, including the same o-MMT used in the current study [31]. All of these mechanisms led to the generation of a larger plastic deformation in the studied films which induced increasing $\beta w_{\mathrm{p}}$ values with o-MMT content.

Although an obvious contribution of the o-MMT particles was observed in the increasing toughness of 'equilibrated aged' PLA samples, the effect of the o-MMT on the PLA physical aging kinetics should also be considered. 


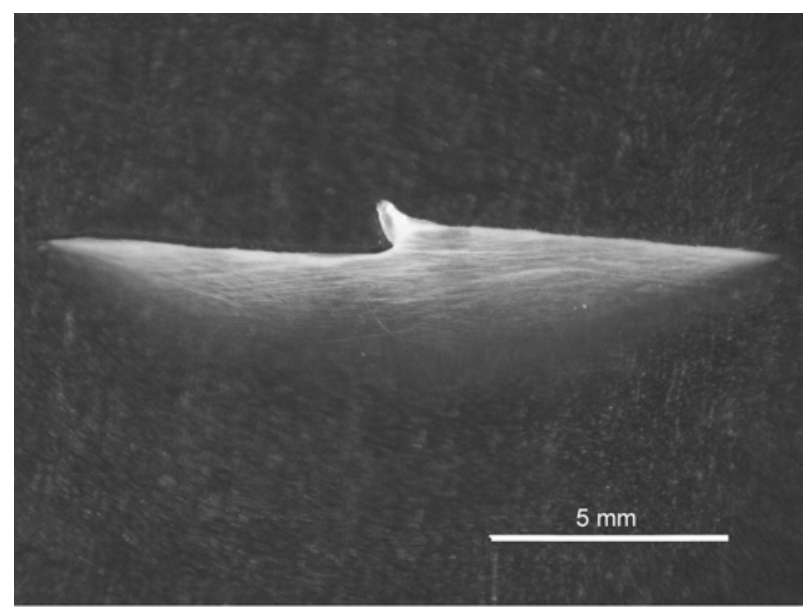

a)

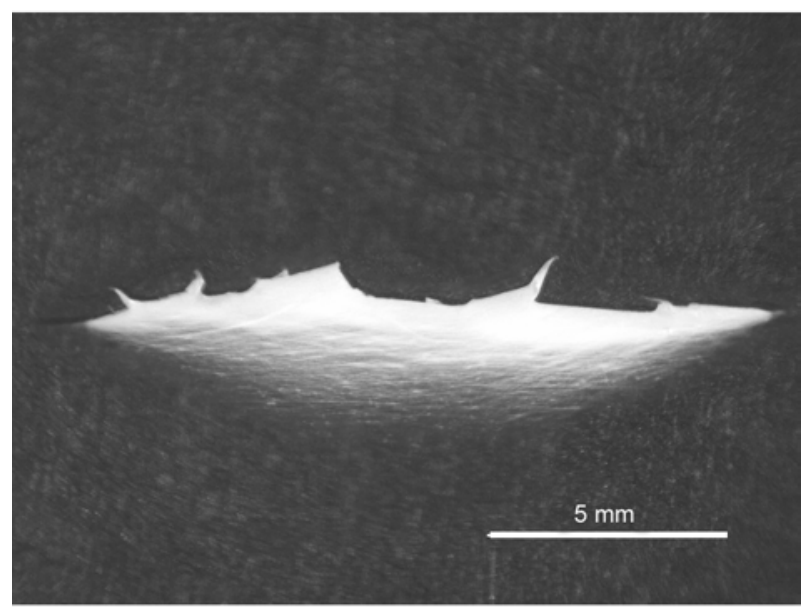

b)

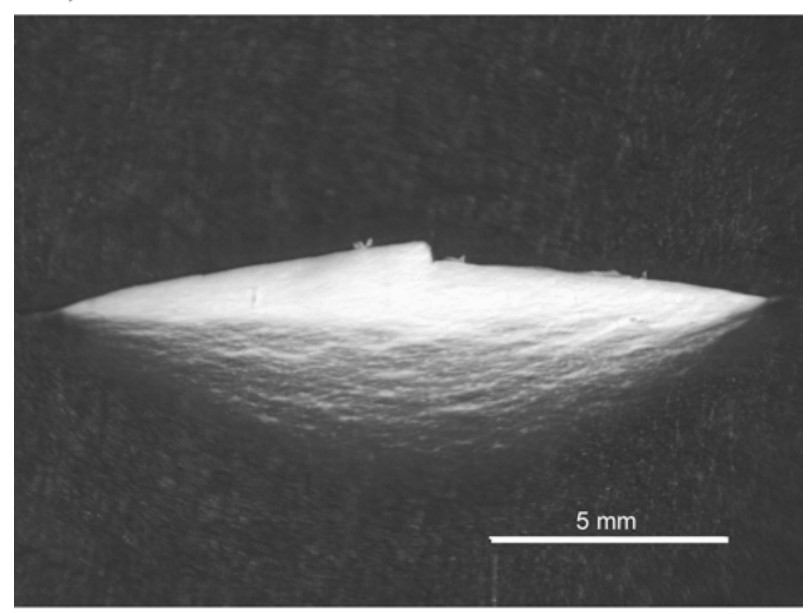

c)

Figure 6. Optical micrographs of the process zone after testing of a) PLA; b) PLA-C0.5; and c) PLAC2.5

Regarding aged samples for different $t_{\mathrm{a}}(24,48 \mathrm{~h}, 7$ and 20 days), an attempt to perform an EWF analysis was done. However, non-consistent self-similar curves and erratic strain field distributions in the OPDZ and in the inner fracture process zone (IFPZ) were measured. This finding was attributed to the transient behaviour from ductile to brittle.

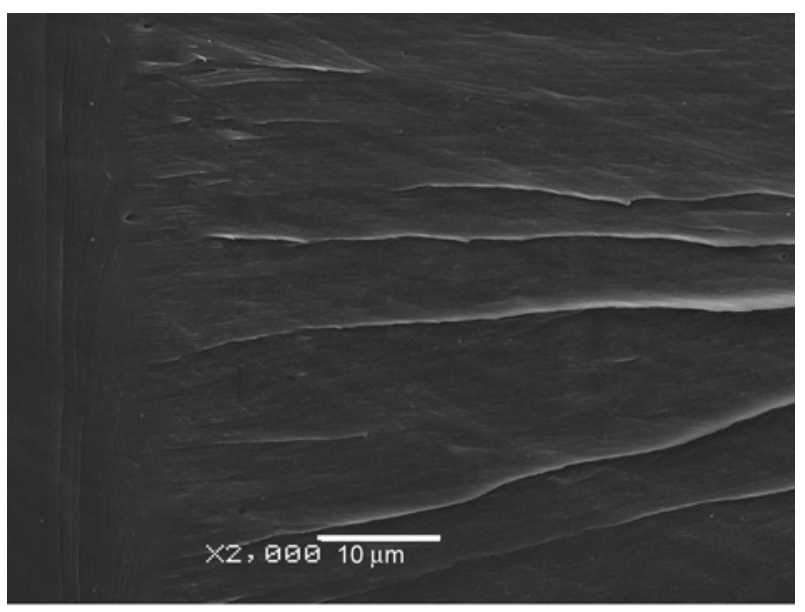

a)

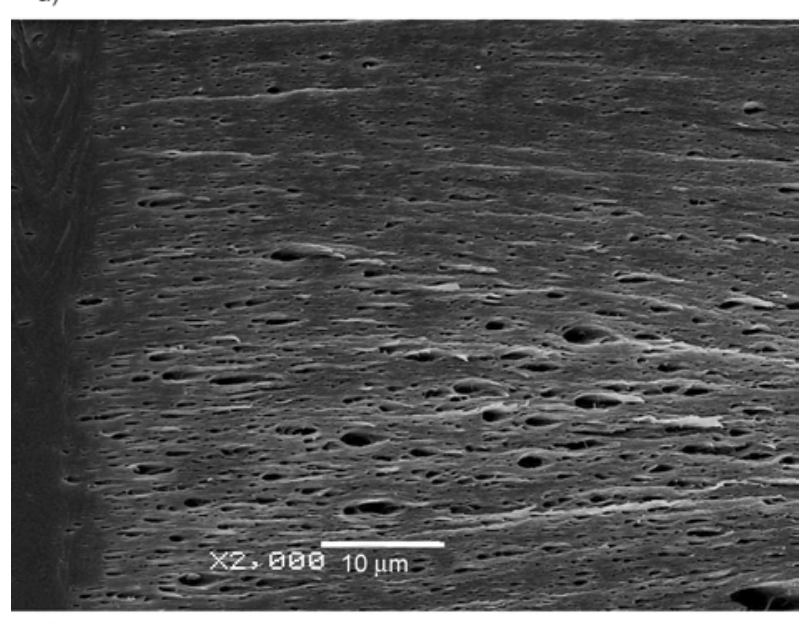

b)

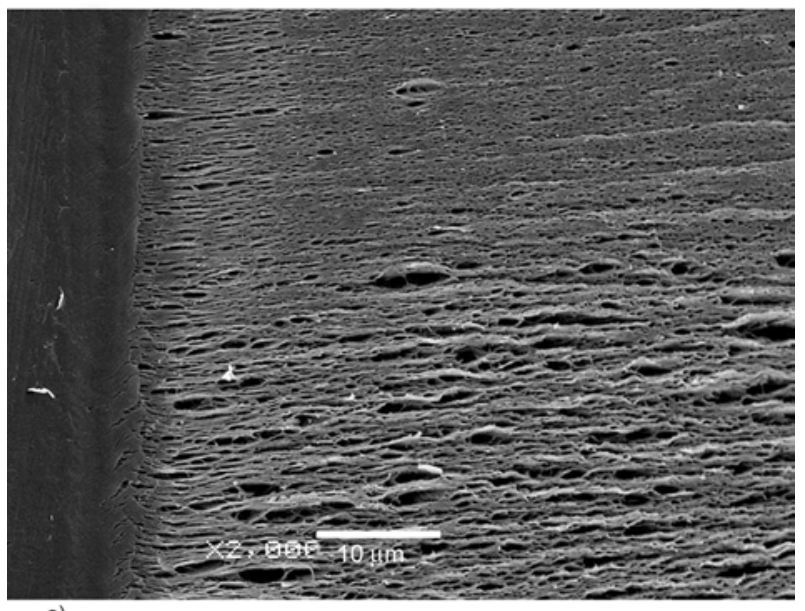

c)

Figure 7. SEM micrographs of the fracture surface of a) PLA; b) PLA-C0.5; and c) PLA-C2.5

As SPT experiments are less time consuming than EWF tests, the transient mechanical behaviour at a predetermined $t_{\mathrm{a}}$ may be monitored with more accuracy. Therefore, this work was complemented with SPT experiments in order to investigate the transient fracture behaviour. 


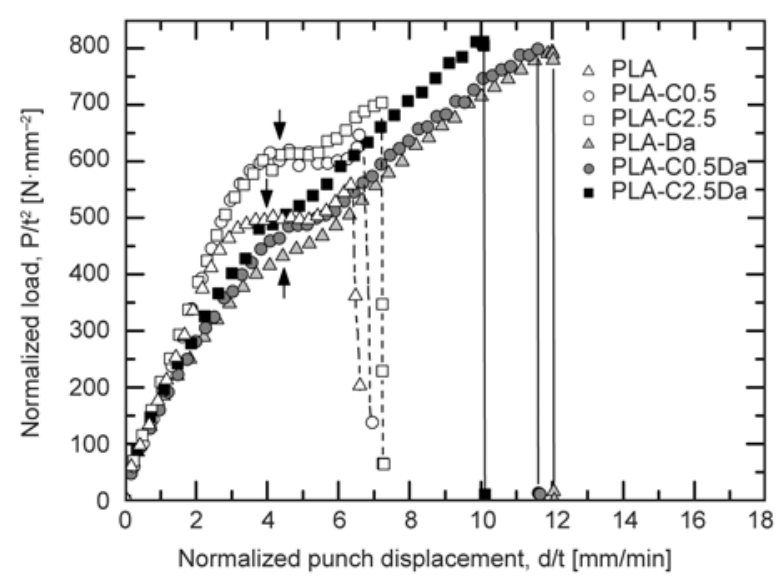

Figure 8. Typical SPT curves normalized by specimen thickness for 'equilibrated aged' and 'de-aged' materials. Arrows indicate the yielding region.

Figure 8 displays representative SPT load-punch displacement curves of all investigated samples. Regarding 'equilibrated aged' samples, the load increased and reached a first maximum value $\left(P_{\mathrm{y}}\right.$, indicated by an arrow) upon loading. Then, after a small load drop, a new increase in the load was registered until the final rupture of the sample. This last situation seems to indicate that a strain hardening process was taking place upon loading.

By comparing SPT curves to those of a conventional tensile test for these samples [32], a possible correlation may be established between the zone around $P_{\mathrm{y}}$ in SPT and the yield zones in the tensile tests.

The SPT load-punch displacement curves of 'deaged' materials slightly differ from those of the 'equilibrated aged' samples. While de-aged samples exhibited a significant decrease in stiffness (slope in the initial zone of the curve), a considerable increase in ductility (displacement at break) was measured. The described behaviour is clearly appreciable for pristine samples. Moreover, the yielding zone is not easily observed due to a constant increase in the load with respect to the punch displacement upon loading. It is believed that yielding and strain hardening processes occurred simultaneously.

Figure 9 shows the variation of normalized work at break $\left(W_{\mathrm{b}} / t^{2}\right)$ with respect $\left(t_{\mathrm{a}}\right)$. Unlike EWF results, $W_{\mathrm{b}} / t^{2}$ exhibited similar values during the first $17 \mathrm{~h}$ (0.7 days) for all samples. Then, pristine PLA samples showed a monotonous decrease of $W_{\mathrm{b}} / t^{2}$ with $t_{\mathrm{a}}$ up to 42 days, where an equilibrated state seemed to be reached. A completely different scenario was observed for PLA/o-MMT samples. The presence

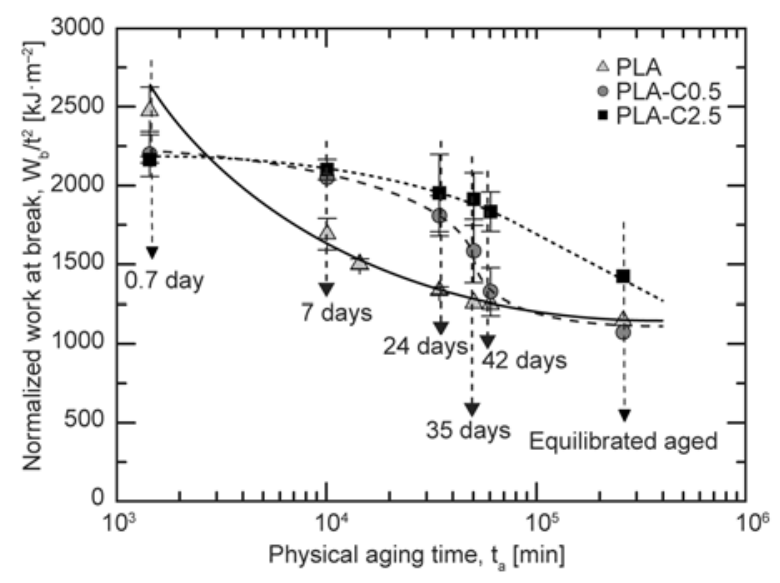

Figure 9. Variation of the normalised work at break $\left(W_{\mathrm{b}} / t^{2}\right)$ vs. aging time $\left(t_{\mathrm{a}}\right)$

of o-MMT seems to decelerate the trend previously described; this was more noticeable for larger amounts of o-MMT. After 7 days, PLA-C2.5 has a loss of only $3 \%$ of the aforementioned parameter and $7 \%$ in the case of PLA-C0.5. At 35 days the PLAC2.5 still exhibits a rather ductile behaviour with a loss of $12 \%$ in $W_{\mathrm{b}} / t^{2}$, while PLA-C 0.5 has an intermediate behaviour, reporting a loss of $28 \%$.

After 42 days $\left(6 \cdot 10^{4} \mathrm{~min}\right)$ the $W_{\mathrm{b}} / t^{2}$ value of PLAC 0.5 converged to the one of unfilled PLA, while for PLA-C2.5 no such trend was observed. The 'equilibrated aged' group of samples (tested at $t_{\mathrm{a}}=$ 6 months), showed very similar values between PLA and PLA-C0.5 and still a larger value for PLA-C2.5, which is in line with the we trend previously reported (c.f. Table 1).

Taking into account these results, three questions arise: Does o-MMT only change the failure mode, thereby influencing toughness?; 2) Does o-MMT affect the kinetics of physical aging?; or 3) Do both mechanisms operate simultaneously?

In order to answer these questions and to obtain more information about the physical aging process, the rate of enthalpy relaxation $\left(\beta_{\mathrm{H}}\right)$, associated to the aging kinetics, was determined using DSC measurements. Based on the heating scans of samples aged at $30^{\circ} \mathrm{C}$ during different and well controlled $t_{\mathrm{a}}$, enthalpy relaxation $\left(\delta_{\mathrm{H}}\right)$ was determined for each aged sample and plotted as a function of $\log t_{\mathrm{a}}$ (Figure 10). From the slope of this linear representation the $\beta_{\mathrm{H}}$ value was determined $[13,17,29]$.

As shown in Figure 10, only PLA samples exhibited a nearly linear relation in the whole range of $t_{\mathrm{a}}$ considered. Similar behaviour has been reported by Cailloux et al. [17] up to 6 months. However, this 


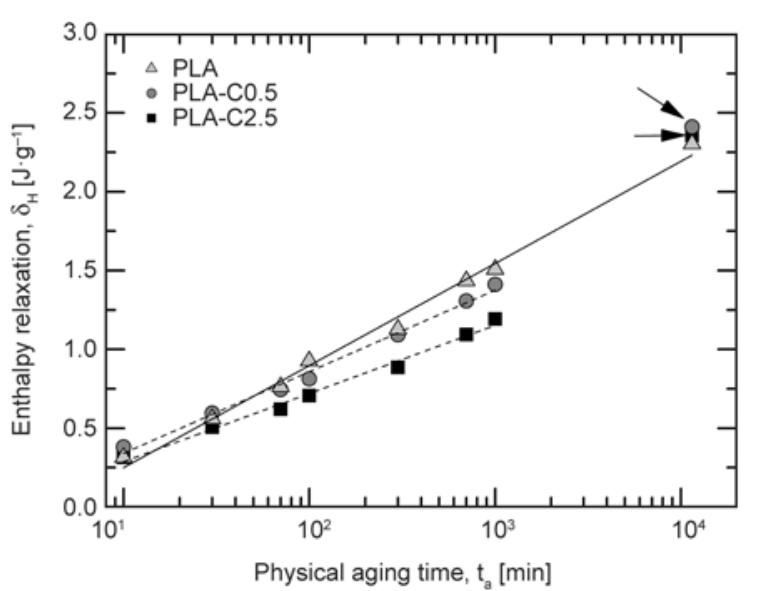

Figure 10. Determination of the rate of enthalpy relaxation $\left(\beta_{\mathrm{H}}\right)$ from the enthalpy relaxation $\left(\delta_{\mathrm{H}}\right)$ versus $\log t_{\mathrm{a}}$. For PLA-oMMT materials, values indicated by the arrow were not taken into the linear fitting. Relative errors of all $\delta_{\mathrm{H}}$ measurement were lower than $5 \%$.

behaviour changed substantially with the incorporation of o-MMT. For PLA/o-MMT films, the linear relationship between $\delta_{\mathrm{h}}$ and $\log t_{\mathrm{a}}$ remained solely valid up to $17 \mathrm{~h}\left(10^{3} \mathrm{~min}\right)$. For longer $t_{\mathrm{a}}\left(10^{4} \mathrm{~min}\right)$ the measured enthalpy relaxation converged to the values obtained for unfilled PLA (indicated by the arrows in Figure 10).

As compared to PLA samples, the non-linearity exhibited by all PLA/o-MMT samples suggest that the overall rate of enthalpy relaxation should be described by at least two values in the range of $t_{\mathrm{a}}$ analysed. Nevertheless, for comparative purposes, a linear fitting analysis was performed up to $10^{3} \mathrm{~min}$. Results are given in Table 2. The high correlation coefficient obtained suggests reliable data and the measured $\beta_{\mathrm{H}}$ value for PLA samples was in close agreement with previous works [17].

As shown in Table 2, the rate of enthalpy relaxation decreased with increasing o-MMT content. Although the calculated parameter should be considered only relative, the overall trend of the enthalpy relaxation (or enthalpy recovery) shown in Figure 10 indicates

Table 2. Enthalpy relaxation rate $\left(\beta_{\mathrm{H}}\right)$ at $30^{\circ} \mathrm{C}$ for all investigated samples

\begin{tabular}{|l|c|c|}
\hline \multicolumn{1}{|c|}{ Material } & $\begin{array}{c}\boldsymbol{\beta}_{\mathbf{H}} \\
{\left[\mathbf{J} \cdot \mathbf{g}^{-\mathbf{1}} \text { per decade } \mathbf{m i n}\right]}\end{array}$ & $\boldsymbol{R}^{\mathbf{2}}$ \\
\hline PLA & $0.65 \pm 0.02$ & 0.992 \\
\hline PLA-C0.5 & $0.52 \pm 0.02$ & 0.991 \\
\hline PLA-C2.5 & $0.43 \pm 0.02$ & 0.989 \\
\hline
\end{tabular}

that there is a broader distribution of relaxation times compared to pristine PLA.

This behaviour is in line with the domain relaxation model proposed by Lu and Nutt [33] in their study of epoxy-oMMT nanocomposites. Taking into account that the enthalpy relaxation during the physical aging process is related to the degree of chain segmental relaxation, the lower enthalpy relaxation of PLA/o-MMT composites can be ascribed to the slower relaxation rate of PLA chain segments arising from o-MMT restrictions in this range of $t_{\mathrm{a}}$. According to this model, the rate of these relaxations is expected to vary with the distance from the nanoparticle surface, interaction degree between o-MMT-polymer, and the type of oMMT dispersion (exfoliation or intercalation). In addition, the overall relaxation behaviour of nanocomposites is expected to depend on the ratio of restricted and unrestricted segment numbers which gives rise to a strong dependence on filler content.

As depicted in Figure 10, an equivalent thermodynamical state was measured for all samples aged for 7 days $\left(10^{4} \mathrm{~min}\right)$. Although not shown in this plot, this observation was also verified for longer $t_{\mathrm{a}}$ where a similar value of $\delta_{\mathrm{H}}\left(3.4 \pm 0.2 \mathrm{~J} \cdot \mathrm{g}^{-1}\right)$ was measured for samples aged for 6 months at $30^{\circ} \mathrm{C}$ and $50 \% \mathrm{RH}$. This behaviour suggests that for long annealing times (i.e. $t_{\mathrm{a}} \geq 10^{4} \mathrm{~min}$ ), the $\delta_{\mathrm{H}}$ extend remains uninfluenced by the o-MMT particles but solely by the intrinsic aging kinetics of the PLA matrix.

Regarding mechanical performances, SPT results showed significant differences between pristine PLA and PLA/o-MMT materials aged for $t_{\mathrm{a}} \geq 10^{4} \mathrm{~min}$. As previously observed, these differences could be solely attributed to the toughening effect of the o-MMT and not to a change in the physical aging kinetics of the PLA matrix.

With respect to PLA-C0.5 samples, the toughening effect induced by the o-MMT appeared to be ineffective for $t_{\mathrm{a}} \geq 42$ days. For higher o-MMT contents (PLA-C2.5), the toughening level was almost maintained ( $66 \%$ of the initial values) for samples aged up to 6 months. These observations suggest that the toughening micro-mechanisms promoted by the addition of o-MMT (contribution of cavitation/crazing/shear yielding) are insufficient to compensate or to alleviate the brittleness of PLA matrix due to the physical aging process. 


\section{Conclusions}

The SPT appears to be an effective tool for the mechanical characterization of the ductile-brittle transition during the physical aging at $23 \pm 2^{\circ} \mathrm{C}$ of PLA/o-MMT films. It was possible to evaluate the transient ductile-to-brittle behaviour and the necessary time to complete the aforementioned transition.

During the first $17 \mathrm{~h}$, the enthalpy relaxation analysis indicated that the rate of physical aging decreased with increasing o-MMT content. From a thermodynamical point of view, all systems were equivalent after being aged for 1 week. However, in terms of mechanical performance, significant differences were observed. These mechanical differences could not only be attributed to the change in the kinetics of the physical aging process, but also to the toughening mechanisms involved: o-MMT/matrix debonding or cavitation and simultaneous multiple crazing as well as shear yielding of the PLA matrix.

\section{Acknowledgements}

The authors would like to acknowledge the financial support from the Ministerio de Economía y Competitividad (Government of Spain) through the projects: MAT2010-19721C02-01, MAT2011-28796-C03-03, MAT2013-40730-P.

\section{References}

[1] Garlotta D.: A literature review of poly(lactic acid). Journal of Polymers and the Environment, 9, 63-84 (2001).

DOI: 10.1023/A:1020200822435

[2] Auras R., Harte B., Selke S.: An overview of polylactides as packaging materials. Macromolecular Bioscience, 4, 835-864 (2004). DOI: $10.1002 / \mathrm{mabi} .200400043$

[3] Briassoulis D.: An overview on the mechanical behaviour of biodegradable agricultural films. Journal of Polymers and the Environment, 12, 65-81 (2004). DOI: 10.1023/B:JOOE.0000010052.86786.ef

[4] Ogata N., Jimenez G., Kawai H., Ogihara T.: Structure and thermal/mechanical properties of poly(1-lactide)clay blend. Journal of Polymer Science Part B: Polymer Physics, 35, 389-396 (1997).

DOI: 10.1002/(SICI)1099-0488(19970130)35:2<389:: AID-POLB14>3.0.CO;2-E

[5] Karger-Kocsis J., Kéki S.: Biodegradable polyesterbased shape memory polymers: Concepts of (supra) molecular architecturing. Express Polymer Letters, 8, 397-412 (2014).

DOI: $10.3144 /$ expresspolymlett.2014.44
[6] Imre B., Renner K., Pukánszky B.: Interactions, structure and properties in poly(lactic acid)/thermoplastic polymer blends. Express Polymer Letters, 8, 2-14 (2014).

DOI: $10.3144 /$ expresspolymlett.2014.2

[7] Cailloux J., Santana O. O., Franco-Urquiza E., Bou J. J., Carrasco F., Gámez-Pérez J., Maspoch M. L.: Sheets of branched poly(lactic acid) obtained by one step reactive extrusion calendering process: Melt rheology analysis. Express Polymer Letters, 7, 304-318 (2013). DOI: 10.3144 /expresspolymlett.2013.27

[8] Raquez J-M., Habibi Y., Murariu M., Dubois P.: Polylactide (PLA)-based nanocomposites. Progress in Polymer Science, 38, 1504-1542 (2013).

DOI: $10.1016 /$ j.progpolymsci.2013.05.014

[9] Miyata T., Masuko T.: Crystallization behaviour of poly(L-lactide). Polymer, 39, 5515-5521 (1998). DOI: 10.1016/S0032-3861(97)10203-8

[10] Lim L-T., Cink K., Vanyo T.: Processing of poly(lactic acid). in 'Poly(lactic acid): Synthesis, structures, properties, processing and applications' (eds.: Auras R., Lim L. T., Selke S. E. M., Tsuji H.) Wiley, Hoboken, 189-215 (2010).

[11] Lim L-T., Auras R., Rubino M.: Processing technologies for poly(lactic acid). Progress in Polymer Science, 33, 820-852 (2008).

DOI: $10.1016 / \mathrm{j}$. progpolymsci.2008.05.004

[12] Pluta M., Murariu M., Alexandre M., Galeski A., Dubois P.: Polylactide compositions. The influence of ageing on the structure, thermal and viscoelastic properties of PLA/calcium sulfate composites. Polymer Degradation and Stability, 93, 925-931 (2008). DOI: 10.1016/j.polymdegradstab.2008.02.001

[13] Pan P., Zhu B., Inoue Y.: Enthalpy relaxation and embrittlement of poly(L-lactide) during physical aging. Macromolecules, 40, 9664-9671 (2007). DOI: $10.1021 / \mathrm{ma} 071737 \mathrm{c}$

[14] Karger-Kocsis J., Bárány T., Moskala E. J.: Plane stress fracture toughness of physically aged plasticized PETG as assessed by the essential work of fracture (EWF) method. Polymer, 44, 5691-5699 (2003).

DOI: $10.1016 / \mathrm{S} 0032-3861(03) 00590-1$

[15] Bárany T., Ronkay F., Karger-Kocsis J., Czigány T.: In-plane and out-of-plane fracture toughness of physically aged polyesters as assessed by the essential work of fracture (EWF) method. International Journal of Fracture, 135, 251-265 (2005).

DOI: $10.1007 / \mathrm{s}$ 10704-005-3947-2

[16] Bárány T., Földes E., Czigány T.: Effect of thermal and hygrothermal aging on the plane stress fracture toughness of poly(ethylene terephthalate) sheets. Express Polymer Letters, 1, 180-187 (2007).

DOI: $10.3144 /$ expresspolymlett.2007.28 
[17] Cailloux J., Santana O. O., Franco-Urquiza E., Bou J. J., Carrasco F., Maspoch M. L.: Sheets of branched poly(lactic acid) obtained by one-step reactive extrusion-calendering process: Physical aging and fracture behavior. Journal of Materials Science, 49, 4093-4107 (2014).

DOI: $10.1007 /$ s10853-014-8101-y

[18] Gamez-Pérez J., Velazquez-Infante J. C., FrancoUrquiza E., Pages P., Carrasco F., Santana O. O., Maspoch M. L.: Fracture behavior of quenched poly (lactic acid). Express Polymer Letters, 5, 82-91 (2011).

DOI: 10.3144/expresspolymlett.2011.9

[19] Giddings V. L., Kurtz S. M., Jewett C. W., Foulds J. R., Edidin A. A.: A small punch test technique for characterizing the elastic modulus and fracture behavior of PMMA bone cement used in total joint replacement. Biomaterials, 22, 1875-1881 (2001).

DOI: 10.1016/S0142-9612(00)00372-0

[20] Jaekel D. J., MacDonald D. W., Kurtz S. M.: Characterization of PEEK biomaterials using the small punch test. Journal of the Mechanical Behavior of Biomedical Materials, 4, 1275-1282 (2011).

DOI: $10.1016 /$ j.jmbbm.2011.04.014

[21] Rodríguez C., Arencón D., Belzunce J., Maspoch M. L.: Small punch test on the analysis of fracture behaviour of PLA-nanocomposite films. Polymer Testing, 33, 21-29 (2014). DOI: $10.1016 /$ j.polymertesting.2013.10.013

[22] Franco-Urquiza E. A., Cailloux J., Santana O., Maspoch M. L., Velazquez Infante J. C.: The influence of the clay particles on the mechanical properties and fracture behavior of PLA/o-MMT composite films. Advances in Polymer Technology, in press (2014). DOI: $10.1002 / \mathrm{adv} .21470$

[23] Martinez A. B., Gamez-Perez J., Sanchez-Soto M., Velasco J. I., Santana O. O., Maspoch M. L.: The essential work of fracture (EWF) method - Analyzing the post-yielding fracture mechanics of polymers. Engineering Failure Analysis, 16, 2604-2617 (2009). DOI: 10.1016/j.engfailanal.2009.04.027

[24] Bárány T., Czigány T., Karger-Kocsis J.: Application of the essential work of fracture (EWF) concept for polymers, related blends and composites: A review. Progress in Polymer Science, 35, 1257-1287 (2010). DOI: $10.1016 /$ j.progpolymsci.2010.07.001
[25] Clutton E. Q.: Essential work of fracture. in 'Fracture mechanics testing methods for polymers, adhesive and composites' (eds.: Moore D. R., Pavan A., Williams J. G.) Elsevier, Oxford, 177-202 (2001).

[26] Gamez-Perez J., Santana O. O., Martinez A. B., Maspoch M. L.: Use of extensometers on essential work of fracture (EWF) tests. Polymer Testing, 27, 491-497 (2008).

DOI: 10.1016/j.polymertesting.2008.02.002

[27] Rodríguez C., Cárdenas E., Belzunce F. J., Betegón C.: Experimental determination of the fracture toughness of steels by means of the small punch test. Experimental Mechanics, 53, 385-392 (2013).

DOI: $10.1007 / \mathrm{s} 11340-012-9637-\mathrm{x}$

[28] García T. E., Rodríguez C., Belzunce F. J., Suárez C.: Estimation of the mechanical properties of metallic materials by means of the small punch test. Journal of Alloys and Compounds, 582, 708-717 (2014).

DOI: $10.1016 /$ j.jallcom.2013.08.009

[29] Hutchinson J. M.: Physical aging of polymers. Progress in Polymer Science, 20, 703-760 (1995). DOI: 10.1016/0079-6700(94)00001-I

[30] Karger-Kocsis J., Czigany T.: Strain rate dependence of the work of fracture response of an amorphous poly (ethylene-naphthalate) (PEN) film. Polymer Engineering and Science, 40, 1809-1815 (2000).

DOI: $10.1002 /$ Pen.11312

[31] Karger-Kocsis J., Khumalo V. M., Bárány T., Mészáros L., Pegoretti A.: On the toughness of thermoplastic polymer nanocomposites as assessed by the essential work of fracture (EWF) approach. Composite Interfaces, 20, 395-404 (2013). DOI: $10.1080 / 15685543.2013 .807145$

[32] Santana O. O., Rodríguez C., Belzunce J., GámezPérez J., Carrasco F., Maspoch M. L.: Fracture behaviour of de-aged poly(lactic acid) assessed by essential work of fracture and J-integral methods. Polymer Testing, 29, 984-990 (2010). DOI: $10.1016 /$ j.polymertesting.2010.09.004

[33] Lu H., Nutt S.: Restricted relaxation in polymer nanocomposites near the glass transition. Macromolecules, 36, 4010-4016 (2003).

DOI: $10.1021 / \mathrm{Ma} 034049 \mathrm{~b}$ 